\title{
$\delta$-鉄の酸素溶解度におよぼす第三元素の影響*
}

\author{
西川 潔**。草野昭彦***。伊藤公允 ${ }^{* * * *}$ 。佐野幸吉 $* * * * *$
}

\section{Effect of the Alloying Elements on the Solubility of Oxygen in $\delta$-Iron}

\section{Synopsis}

\author{
kiyoshi Nishikawa, Akihiko Kusano, Köin Ito, and Kōkichi Sano
}

Non metallic inclusions change their composition in solid iron during annealing at high temperatures. Therefore, it is desirable to know the effects of the alloying elements on the oxygen in solid iron. This experiment was carried out to know the effect of the alloying elements on the solubility of the oxygen and to determine the interaction coefficients of oxygen in $\delta$-iron. The crucible assembly was lowered very slowly under purified argon gas in Tamman furnace and the equilibrium between solid iron and liquid was observed. The relation of the distribution ratio of oxygen in $\mathrm{Fe}-\mathrm{O}$ system $\left(L o^{\prime}\right)$ and in $\mathrm{Fe}-\mathrm{O}-\mathrm{X}$ system $(L o)$ is

$$
\log L o=\log L o^{\prime}+\log \frac{f_{l}^{(\mathrm{X})}}{f_{S}^{(\mathrm{X})}}
$$

where $f_{S}^{(X)}$ and $f_{l}^{(X)}$ are the interaction coefficients in solid and liquid iron respectively. By using the relation, we can get the interaction coefficients in solid iron. These results are as follows:

$$
\begin{aligned}
& \log f_{S}^{(\mathrm{Mn})}=-1.83 \quad[\% \mathrm{Mn}]<0.15 \% \\
& \log f_{S}^{(\mathrm{Cr})}=-0.23 \quad\left[\begin{array}{ll}
\% & \mathrm{Cr}
\end{array}\right]<0.5 \% \\
& \log f_{S}^{(\mathrm{Si})}=-12 \cdot 14 \quad[\% \mathrm{Si}] \quad<0 \cdot 1 \% \\
& \log f_{S}^{(\mathrm{V})}=-1.71 \quad\left[\begin{array}{ll}
\% & \mathrm{~V}]
\end{array}<0.3 \%\right. \\
& \log f_{S}^{(N 1)}=-0.105 \quad[\% \mathrm{Ni}] \quad<1.0 \%
\end{aligned}
$$

(Received Apr. 22, 1969)

\section{1. 緒言}

銅中に存在する酸化物系非金属介在物を考える上で， その酸化物を形成している酸素とMn，Si などの第 3 元 素との間の相互作用を知ることは重要である．溶鉄中の 酸素の活量係数に及ぼす第 3 元素の影響については種々 の研究者によつてかなり正確に調べられているが. 固体 鉄中のそれについてはあまり調べられていない。しかる に鋼の製品にいたるまでの種々の熱処理過程において， 固体鉄中で非金属介在物はその組成を变化することが知 られている1．これらの介在物の固体鉄中における熱的 挙動を知るためには，固体鉄中の酸素と第 3 元素との間 の相互作用を定量的に知ることが望まれる.

固体鉄中の窒素2) 8) や硫黄9)10)11) と合金元素との間の 相互作用については, 気相と固相の直接平衡により種々 の研究者により求められているが，気相と固相との平衡 においては平衡到達時間の長いこと, 気相雾囲気の調整 がむずかしいこと，固相中の不純物元素の影響の大なる ことなど，問題となることが多い，金属溶液の液相にお ける原子の相互作用と固相における原子の相互作用との 差を熱力学的に推定して ${ }^{11)}, \mathrm{Fe}-\mathrm{C}-\mathrm{X}$ 系, $\mathrm{Fe}-\mathrm{N}-\mathrm{X}$ 系に ついて計算したものもある13).
前報14)においては，タンマン炉を用いてアルゴンガス 雲囲気中でルツボを下降することにより，炉の温度勾配 を利用して，固相一液相間の平衡を行ない，固液分配比 を求め， $\delta$ 鉄中の酸素溶解度を決定した。 また第 3 元素 として Cr をとりあげその影響を報告した．本研究にお いては，さらに第 3 元素として， $\mathrm{Mn}, \mathrm{Si}, \mathrm{V}, \mathrm{Ni}$ をと りあげ，それらの元素の酸素の固液分配比に及ぼす影響 を調べ，その值を用いてそれらの元素の $\delta$ 鉄中における 酸素への相互作用係数を決定した.

\section{2. 実}

験

実験に使用した装置は前報 ${ }^{14)}$ と同様である. 実験方法 は前報14)で第 3 元素として Cr を添加した場合と同様 で，溶鉄表面にスラグを浮かせ，酸素飽和状態で実験を 行なつた. その場合, 固相, 液相に酸素は完全に固溶し ている必要があり，化合物（酸化物）が存在してはなら

* 昭和 44 年 3 月本会講演大会にて発表 昭和 44 年 4 月 22 日受付

** 名古屋大学大学院

*** 八幡製鉄 (株) 戸畑製造所

**** 名古屋大学工学部 工博

***** 名古屋大学工学部 理博 
ない.これは, 前報14)の Photo. 2 に示してあるように, 固相中には酸化物はほとんど存在しておらず，酸素は地 鉄に完全に固溶していると考えることができる．また Photo. 2.の液相の部分に見られる酸化物は，凝固時に生 成したもので，固相，液相を平衡させている液相中には 酸化物は存在していないと考えることができる．たとえ 液相中に酸化物が存在したとしても，本実験のように長 時間放置すれば，それらは浮上することができる.

用いた添加物は次のごとくである.
1) 電解マンガン
$99 \cdot 9 \%$ 以上
2) 電解ニッケル $99 \cdot 98 \%$ 以上 $+\mathrm{Co}$
3 ）金属シリコン $98 \%$
$4 ）$ 金属バナジウム

さらに酸素濃度調整のために次のものを添加した。

1) 酸化第二鉄 $99 \%$ 以上

2 ) 二酸化マンガン $99 \cdot 0 \%$ 以上

3）酸化ニッケル 硝酸ニッケルを酸素雾囲 気中で加熱し, $300^{\circ} \mathrm{C} \sim 600^{\circ} \mathrm{C}$ に保持して, 水分および $\mathrm{NO}_{2}$ を発生させて分解し，その 後酸素流量を多くして完全に酸化させたも の.

分析方法は次のごとくである.
1) 酸素
真空溶融法

ただし，Mnを含む試料の場合は，Mn の蒸発が大きく それが反応管に蒸着するため，抽出されるCO ガスがそ れに吸着し，酸素の值は低くなるとされている。これを 防止するため，的場，郡司15)らの方法を採用し，金属す ず 1〜2g を試料と同時に溶融して蒸着膜のガス吸収を 軽減した。

2) マンガン

吸光光度法（JIS, G 1213)

3) シリコン

モリブデン青法

4) ニッケル

ジメルグリオキシ 么法

5) バナジウム

リンバナドタングス テン酸法

\section{3. 実 験 結 果}

\subsection{Fe-Mn-O 系について}

$\mathrm{Fe}-\mathrm{Mn}-\mathrm{O}$ 采の㠜固温度はわ からないので別にいろいろの

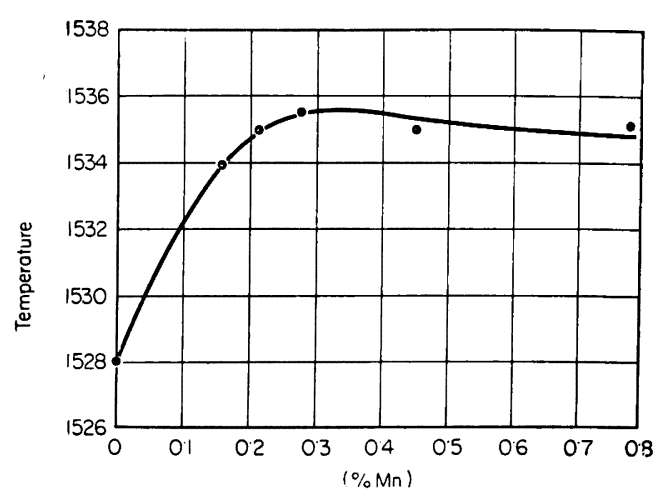

Fig. 1. The relation between freezing temperature and the concentration of manganese in $\mathrm{Fe}-\mathrm{Mn}-\mathrm{O}$ system.

Mn 濃度で酸素を飽和させた（溶鉄の上にスラグを浮か せた状態）溶鉄の冷却曲線を描くことにより凝固開始温 度を求めたものが Fig.1 である. Fig.1 1 以みられるよう に Mn 0.3\% 付近で㠜固開始温度のピークがある.これ は Fig. 2 に示すような Fe-Mn-O 系の三元系状態図か ら説明できる．Fig. 2 に示す状態図で太い実線で描いた 曲線は，Fig.1 の実験曲線を書き入れたものである。こ の図から Fig. 1 で示される冷却曲線(太線) は，Mn 濃 度が零のときの酸素浱度 $0 \cdot 16 \%, 1528^{\circ} \mathrm{C}$ から出発し， $\mathrm{Mn}$ 濃度の上昇とともに, Fig. 2 に示される 2 つの山の 交線を辿つて進んでいく，その際 $\mathrm{Mn} 0.3 \%$ 付近までは 等温線の密なところを通つて急上昇し， $\mathrm{Mn} 0.3 \%$ 付近 でピークとなり, その後等温線は粗となり, 温度は徐々 に下がつていく，前報14)で $\mathrm{Fe}-\mathrm{Cr}-\mathrm{O}$ 系に㧍ける液相の $\mathrm{Cr}$ 濃度と凝固開始温度との関係において，Cr が $3 \%$ 付近まで，漸減するように描いたが，上記に 対応する

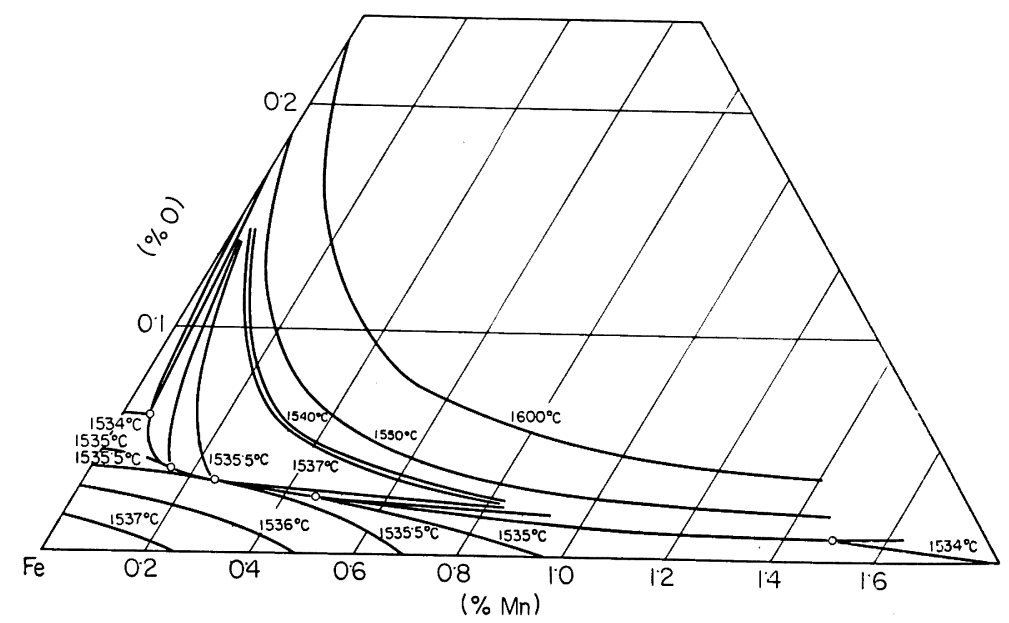

Fig. 2. The diagram of $\mathrm{Fe}-\mathrm{Mn} \sim \mathrm{O}$ system. 
$\mathrm{Fe}-\mathrm{Cr}-\mathrm{O}$ 系三元系状態困から考えると $\mathrm{Cr}$ が $1 \%$ 以下 の浱度範囲で温度のピークがあると思われる．

次に Fig. 3 に固-液分配比 $L o=C_{S} / C_{l}$ に及ぼす $\mathrm{Mn}$ の 影響を示す。これによると Mnが0.1\%までは, $\log L o$ は直線的に上昇するが，それをすぎるとほほ一定值とな つた.この場合の実験值を $\mathrm{Fe}-\mathrm{Mn}-\mathrm{O} 3$ 元系状態図にプ ロットしたものを Fig. 4 に示す. 黒丸は液相組成を示 し, 白丸はそれに対応する固相の組成を示す. 液相組成 は，Fig. 2 亿おける酸素飽和の泠却曲線上にある. 破線 は， $1528^{\circ} \mathrm{C}$ における $\mathrm{Fe}-\mathrm{O}$ 系の固相酸素濃度 ${ }^{14)}(0.012$ $\%)$ と $\mathrm{Fe}-\mathrm{Mn}$ 系の固相 $\mathrm{Mn}$ 濃度 (0.4\%) をそれぞれ 状態図よりもとめ，それらを直線で結び， Fe-Mn-O 采

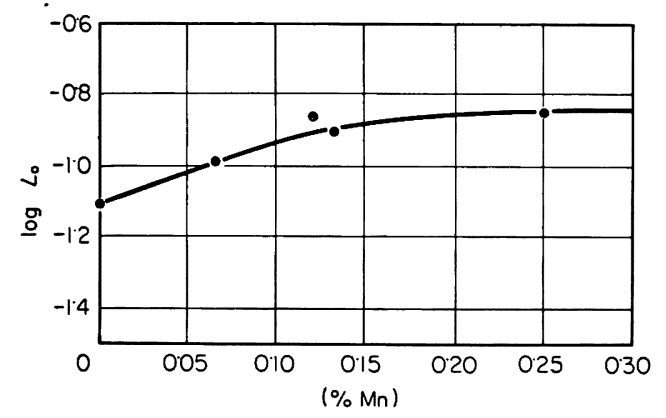

Fig. 3. The effect of the concentration of manganese in solid phase on the distribution ratio of oxygen.

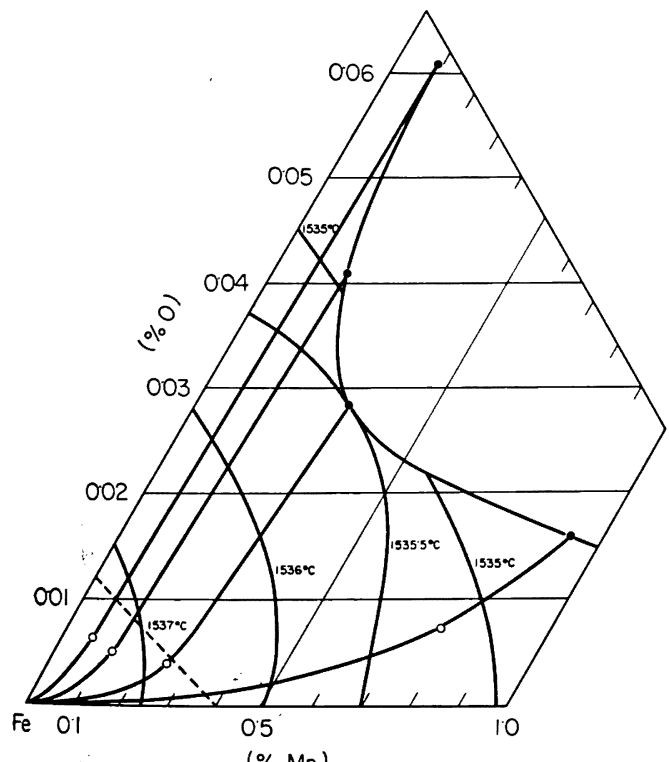

$(\% \mathrm{Mn})$

Fig. 4. The composition of solid phase and liquid existing in equilibrium.
の固相面を推定したものである. 本実験で得られた固相 濃度は，それぞれここで推定した固相面の上に存在する と考えられる. $\mathrm{Mn}$ が高裖度となると，用いた $\mathrm{MgO}$ る つぼや，熱電対の $\mathrm{Al}_{2} \mathrm{O}_{3}$ 保護管がひどくおかされて， 浮いているスラグが， $\mathrm{FeO}-\mathrm{MnO}$ 采以外の酸化物を含え だものとなり，実験点が大きくずれている.

ここで Lo はむろん温度に依存しているが，Fe-X-O 系の純 $\mathrm{Fe}$ 角から下がる固相面, 液相面が, $1538^{\circ} \mathrm{C}$ (前 報14)で求めた純 $\mathrm{Fe}$ の融点）を通る直線が母線となるよ うな円錐面, 楕丹錐面であると近似すれば Lo 注温度によ らず一定と考えることができる．この近似は前報14) $\mathrm{Fe}$ O系の固相線，液相線の直線性から推すことができるよ うに，かなりよい近似であると思われる。したがつて本 研究における Lo 法温度の依存性は無視しているが， $\delta$ 鉄の温度範囲において適用できると思われる。

\subsection{Fe-Ni-O, Fe-Si-O, Fe-V-O 系について}

Ni は鉄とよく似た元素であるため，酸素に対してあ まり大きな影響は与えないように思われる。また溶鉄中 の酸素の活量倸数に及ぼす $\mathrm{Ni}$ の影響については，坂尾， 佐野が述べているように

$$
e_{o}^{\mathrm{Ni}}=0 \cdot 005\left(1600^{\circ} \mathrm{C}\right)<25 \% \mathrm{Ni}
$$

となり正である. そのため $\mathrm{Cr}, \mathrm{Mn}, \mathrm{Si}, \mathrm{V}$ とは違つた 挙動を示すものと思われる. $\log L o$ に及ぼす $\mathrm{Ni}$ の影響 を Fig. 5 に示す. $\mathrm{Ni}$ を添加しても Lo は $\mathrm{Fe}-\mathrm{O}$ 系に おける $0.076\left(\log L_{o}^{\prime}-1 \cdot 12\right)$ なる值からあまり大きく 変化しておらず，しかもLo は $\mathrm{Cr}, \mathrm{Mn}, \mathrm{Si}, \mathrm{V}$ の場合 とは逆に，Ni 濃度が増すにつ机て Lo は減少し，1·0\% をこえるとほとえど一定となる。

$\mathrm{Si}$ は酸素との 親和力が強いため溶鉄中の酸素濃度を きわめて低くし，そのため固体鉄中の酸素を問題として いる本実験では $0.1 \%$ 以上の $\mathrm{Si}$ 濃度になると酸素濃度 が低くなり，酸素分析誤差が大きくなる，そのため本実

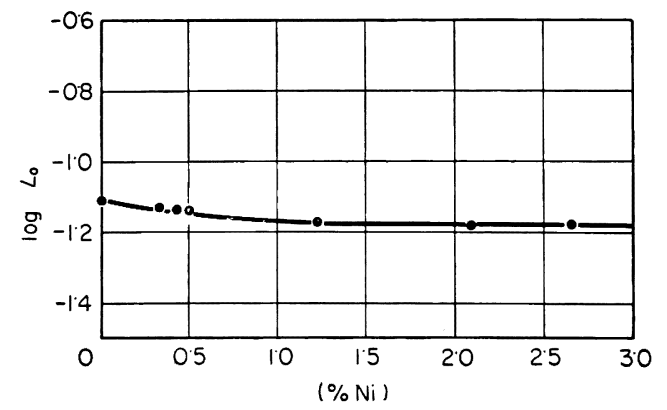

Fig. 5. The effect of the concentration of nickel in solid phase on the distribution ratio of oxygen. 


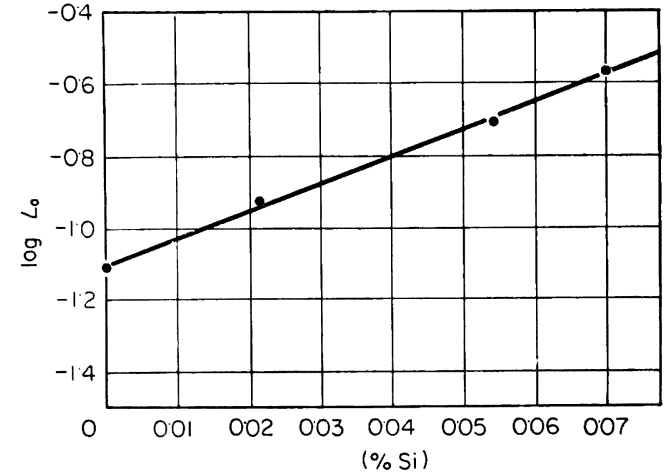

Fig. 6. The effect of the concentration of silicon in solid phase on the distribution ratio of oxygen.

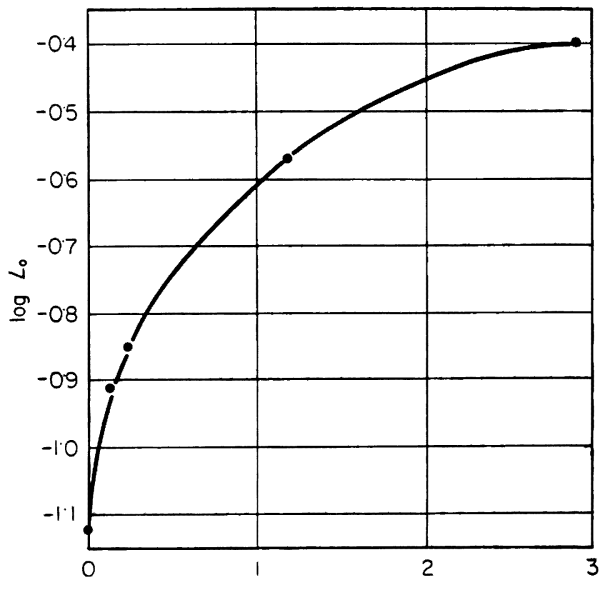

(\%v)

Fig. 7. The effect of the concentration of vanadium in solid phase on the distribution ratio of oxygen.

験では，Si にして 0.1\% 以下の濃度範囲において行な つた. $\log L o$ と固相中の $\mathrm{Si}$ との関係を Fig. 6 に示す。

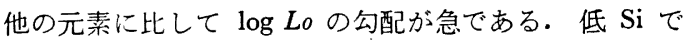
$\log L o$ と $\mathrm{Si}$ との関係はほぼ直線関係である.

$\mathrm{Cr}$ と性質の似ているV について同様の実験を行なつ た. $\log L o$ と固相 $\mathrm{V}$ 濃度との関倸を Fig. 7 に示す. V が $0.2 \%$ 付近までは Mn とよく似た傾向を示し, 直線 関係が成り立つている。

\section{4. 考察}

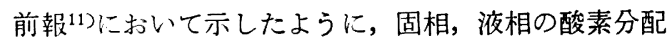
比は，液相の酸素浱度に応じて変化せず，したがつて温 度に依存していない．また第 3 元素が添加された場合も このことが成り立ち, 近似的に温度に分配比は依存して
いないと考えることができる．本実験においては，鋼中 の不純物元素あるいは添加元素がその分配比にいかに影 響を与えるかを示した. Fig. 8 は第 3 元素 [X] の種類 により，分配比がいかに変化するかを低濃度域で示した ものである.これからわかるように， Ni だけが他の元 素とまつたく違つた傾向をもち, 浱度の増加とともに, 分配比は減少する.このことは固体鉄中における相互作 用係数から次のように説明される.

まず $\mathrm{Fe}-\mathrm{O}$ 系について，液相中の酸素 $\underline{\mathrm{O}}(l)$ と固相 中の酸素 $\underline{\mathrm{O}}(s)$ との平衡を考えると, 次式で成り立つ.

$$
\begin{aligned}
& \underline{\mathrm{O}}(l) \rightleftarrows \underline{\mathrm{O}}(s) \\
& a_{l}=f^{\prime}{ }_{l}[\% \mathrm{O}]_{l} \\
& a_{s}=f^{\prime}{ }_{s}[\% \mathrm{O}]_{s}
\end{aligned}
$$

ここで $a_{l}$ は液相中の酸素の活量, $a_{s}$ は固相中の酸素の. 活量, $f_{l}^{\prime}$ 溶鉄中の酸素の活量係数, $f_{s}^{\prime}$ は固相中の酸 素の活量係数で, いずれも無限希釈状態を標準状態とし ている.また液相, 固相の酸素の化学ポテンシャルは次 のごとく表わされる.

$$
\begin{aligned}
& \mu_{l}=\mu_{l}^{o}+R T \ln a_{l} \\
& \mu_{s}=\mu_{s}^{o}+R T \ln a_{s}
\end{aligned}
$$

ここで $\mu^{0}$ 淀数である. 固相, 液相の平衡が成り立つ ているとすると, 両者の化学 ポテンシャルは等しいか ら,

$$
\mu_{l}=\mu_{s}
$$

したがつて

$$
\begin{aligned}
& \left(\mu_{l}^{o}-\mu_{s}^{o}\right) / R T \\
= & \ln \left(a_{s} / a_{l}\right) \\
= & \ln \left\{\left(f_{s}^{\prime}[\% \mathrm{O}]_{s} /\left(f_{l}^{\prime}[\% \mathrm{O}]_{l}\right)\right\}\right. \\
= & \ln \left\{\left(f_{s}^{\prime} / f_{l}^{\prime}\right) \cdot L_{o}^{\prime}\right\}
\end{aligned}
$$

変形すると

$$
L o^{\prime}=\left(f_{s}^{\prime} / f_{s}^{\prime}\right) \exp \left(\mu_{l}^{o} / \mu_{s}^{o}\right) / R T .
$$

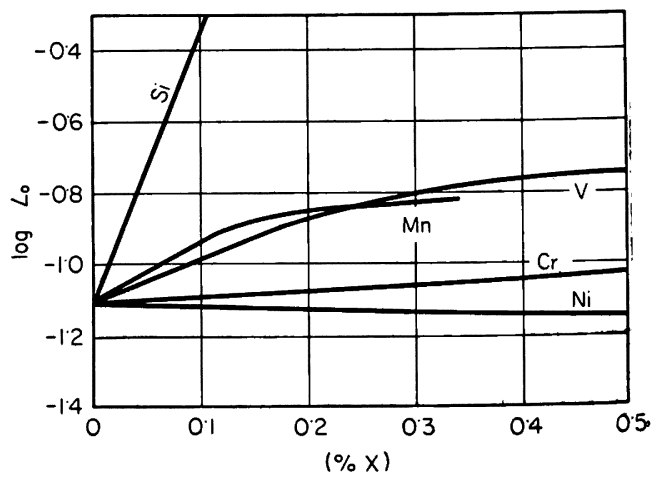

Fig. 8. The effect of the low concentration of alloy elements in solid on the distribution ratio of oxygen. 
次に第 3 元素を添加した場合の $\mathrm{Fe}-\mathrm{X}-\mathrm{O}$ 三元系につ いて考えてみると，前と同様に次のような関係式が得ら れる。

$$
\begin{aligned}
& \underline{\mathrm{O}}(l)_{x} \rightleftarrows \underline{\mathrm{O}}(s)_{x} \\
& a_{l}=f_{l} \cdot f_{l}^{(\mathrm{X})} \cdot[\% \mathrm{O}]_{l(\mathrm{X})} \\
& a_{s}=f_{s}^{\prime} \cdot f_{s}^{(\mathrm{X})} \cdot[\% \mathrm{O}]_{s(\mathrm{x})}
\end{aligned}
$$

ここて $f_{l}^{(X)}$ は液相中の酸素に対する, 元素 $\mathrm{X}$ の相互作 用係数, $f_{s}^{(x)}$ 汢固相中の酸素に対する元素 $\mathrm{X}$ の相互作 用倸数である. $\mathrm{Fe}-\mathrm{O}$ 系の場合と同様に固相，液相の平 衡が成り立つているとき，

$$
\begin{aligned}
& \mu_{l}=\mu_{s} \text { より } \\
& \left(\mu_{l}^{o}-\mu_{s}^{o}\right) / R T \\
& =\ln \left(a_{s} / a_{l}\right) \\
& =\ln \left\{\left(f_{s}^{\prime} \cdot f_{s}^{(\mathrm{X})} \cdot[\% \mathrm{O}]_{s(\mathrm{x})} /\left(f_{l}^{\prime} \cdot f_{l}^{(\mathrm{X})} \cdot[\% \mathrm{O}]_{l(\mathrm{X})}\right)\right\}\right.
\end{aligned}
$$

したがつて

$$
\begin{aligned}
& L o=\left(f_{l}^{(\mathrm{X})} / f_{s}^{(\mathrm{X})}\right) \cdot\left(f_{l}^{\prime} / f_{s}^{\prime}\right) \exp \left(\mu_{l}^{o}-\mu_{s}^{o}\right) / R T \\
& =\left(f_{l}^{(\mathrm{X})} / f_{s}^{(\mathrm{X})}\right) \cdot L o^{\prime}
\end{aligned}
$$

両辺の対数をとれば

$$
\log L o=\log L o^{\prime}+\log \left(f_{l}^{(\mathrm{X})} / f_{s}^{(\mathrm{X})}\right)
$$

(10) 式の意味するところは，第 3 元素 X が入つたとき の分配比 $\log L o$ は， $\mathrm{Fe}-\mathrm{O}$ 二元系における分配比 $\log$ Lo' に $\log \left(f_{l}^{(\mathbf{X})} / f_{s}^{(\mathrm{X})}\right)$ だけ加えてやればよいことにな る. 本実験では, $\mathrm{Cr}, \mathrm{V}, \mathrm{Mn}, \mathrm{Si}$ などの元素は, Fig. 8 に示されているように,

$$
\log L o>\log L o^{\prime} \cdots
$$

になつた．これらの元素は，(11）式が成り立つために は，(10) 式より $\log \left(f_{0}^{(\mathrm{X})} / f_{s}^{(\mathrm{X})}\right)$ が正とならなければ ならない，したがつて， $f_{l}^{(\mathrm{X})}>f_{s}^{(\mathrm{X})}$ が成り立たねばな らない. また Ni は Fig. 8 に示されているように

$\log L o<\log L o^{\prime}$

になつた. (12) 式が成りたつためには, $\log \left(\left(\begin{array}{l}(x) \\ l\end{array} f_{s}^{(x)}\right)\right.$ が負とならなければならない.したがつて $f_{l}^{(x)}<f_{s}^{(x)}$ が成り立た致ばならない。この結果 $\mathrm{Cr}, \mathrm{V}, \mathrm{Si}, \mathrm{Mn} な$ どのように, 液相中において $\mathrm{Fe}$ よりも酸素との親和力 の強いもの $\left(f_{l}^{(\mathrm{X})}<1\right)$ も, $\mathrm{Ni}$ などのように液相中にお いて $\mathrm{Fe}$ よりも酸素との漞和力の弱いもの $\left(f_{l}^{(\mathrm{X})}>1\right)$ も，固相中においてそれぞれさらにその効果をますと考 えることができる。

Fig. 8 に示されるように, 微量の第 3 元素Xに対して 直線関係が成り立ち

$$
\begin{aligned}
\log L o & =\log L o^{\prime}+\log \left(f_{l}^{(\mathrm{X})} / f_{s}^{(\mathrm{X})}\right) \\
& =\log L o^{\prime}+\alpha[\% \mathrm{X}]
\end{aligned}
$$

Fig. 8 より勾配 $\alpha$ を定めれば, $\log \left(f_{l}^{(\mathrm{X})} / f_{s}^{(\mathrm{X})}\right)$ が濃度 [\%X] の関数として求まる. $f_{l}^{(X)}$ を既知のデータから
Table 1. The interaction coefficients in $\delta$-iron.

\begin{tabular}{c|c|c|c|c}
\hline \hline $\mathrm{X}$ & $\log \left(\frac{\left.f_{l}^{(\mathrm{X}}\right)}{f_{s}^{\mathrm{X}}}\right)$ & $\log f_{l}^{(\mathrm{X})}$ & $\log f_{s}^{(\mathrm{X})}$ & Remarks \\
\hline $\mathrm{Mn}$ & $1 \cdot 83[\% \mathrm{Mn}]$ & 0 & $\begin{array}{r}-1 \cdot 83 \\
{[\% \mathrm{Mn}]}\end{array}$ & $<0.15 \%$ \\
\hline $\mathrm{Cr}$ & $0.17[\% \mathrm{Cr}]$ & $\begin{array}{r}-0.055 \\
{[\% \mathrm{Cr}]}\end{array}$ & $\begin{array}{r}-0.23 \\
{[\% \mathrm{Cr}]}\end{array}$ & $<0.5 \%$ \\
\hline $\mathrm{Si}$ & $12[\% \mathrm{Si}]$ & $\begin{array}{r}-0.137 \\
{[\% \mathrm{Si}]}\end{array}$ & $\begin{array}{r}-12 \cdot 14 \\
{[\% \mathrm{Si}]}\end{array}$ & $<0.1 \%$ \\
\hline $\mathrm{V}$ & $1.35[\% \mathrm{~V}]$ & $-0.36[\% \mathrm{~V}]$ & $\begin{array}{r}-1 \cdot 71 \\
{[\% \mathrm{~V}]}\end{array}$ & $<0.3 \%$ \\
\hline $\mathrm{Ni}$ & $\begin{array}{r}-0.10 \\
{[\% \mathrm{Ni}]}\end{array}$ & $0.005[\% \mathrm{Ni}]$ & $\begin{array}{r}0.105 \\
{[\% \mathrm{Ni}]}\end{array}$ & $<1.0 \%$ \\
\hline
\end{tabular}

求めると， $f_{s}^{(\mathrm{X})}$ が計算される (Table 1). Table 1 に は $f_{s}^{(\mathrm{X})}$ の適用範囲も示してあるが，それは $\log L o$ が 第 3 元素 Xに対して直線関係の成り立つ範囲を示す.こ こで $f_{l}^{(X)}$ は固相, 液相平衡温度での值を用いるべきで あるが，液相範囲の $f_{l}^{(\mathrm{X})}$ は $1550^{\circ} \mathrm{C}$ 以上の值しかない ので，近似的に $1550^{\circ} \mathrm{C}$ における值を用いて計算した。 $f_{s}^{(X)}$ は固体内特に凝固点付近における脱酸元素 $\mathrm{Mn}, \mathrm{Si}$ などの酸素に対する相互作用を示すものである. Table 1 を図示すると，Fig. 9 のようになり，Si，Mn が固体 鉄中で酸素に大きな作用を与えることが考えられる.

また $\mathrm{Fe}-\mathrm{X}-\mathrm{Y}-\mathrm{O}$ 四元系においても同様の式が導かれ $\log L o=\log L o^{\prime}+\log \left(f_{l}^{(X)} / f_{s}^{(X)}\right)+\log \left(f_{l}^{\left(Y^{\prime}\right.} / f_{s}^{\left(X^{\prime}\right.}\right)$

$$
=\log L o^{\prime}+\alpha[\% \mathrm{X}]+\beta[\% \mathrm{Y}]
$$

となる.これから三元系の分配比の実験值より四元系の 分配比が推算できる. Fe- V-Cr-O 系により実験值と推 算値の比較は次のようである.

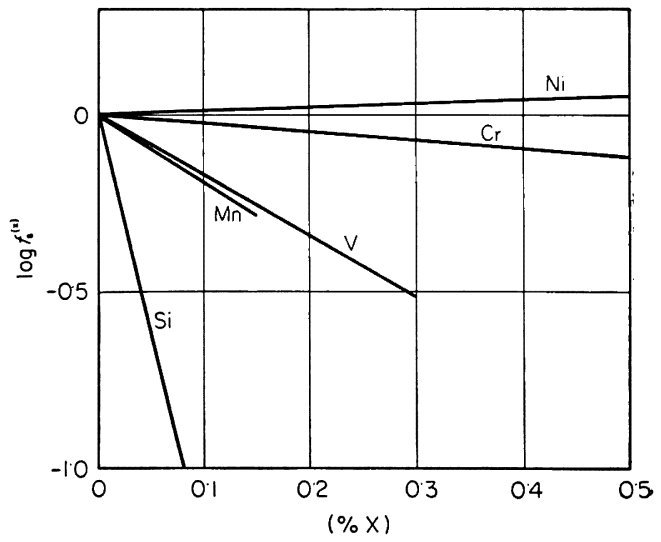

Fig. 9. The effect of the alloy elements on the interaction coefficients in $\delta$-iron. 


$$
\% \mathrm{Cr}=0.097, \% \mathrm{~V}=0.080 \text { のとき }
$$

推算式

$$
\begin{aligned}
\log L o & =\log L o^{\prime}+\alpha[\% \mathrm{~V}]+\beta[\% \mathrm{Cr}] \\
& =-1.12+1.35 \times 0.080+0.17 \times 0.097 \\
& =-0.99
\end{aligned}
$$

実験値

$$
\log L o=-0.75
$$

上記のようにかなりの誤差はあるが，これは $\mathrm{V}, \mathrm{Cr} の$ 間の相互作用を無視していること，また推算式を導くた めの種々の仮定を考えると比較的妥当であると思われ る.この推算式より $\mathrm{Si}, \mathrm{Mn}$ などを同時に含む場合の 固相, 液相の酸素分配比が算出できる.

\section{5. 結言}

$\delta$ 鉄の酸素溶解度に及ぼす第 3 元素の影響を調べ, $\log L o$ と第 3 元素との関係から固体鉄中の酸素の相互 作用係数を計算した. この結果より, 液相中で酸素に対 してあまり大きな相互作用をもたない $\mathrm{Mn}, \mathrm{Si}$ が固相 鉄中では大きな值を示し, 固体鉄での酸素に対する相互 作用が重要であることを示す．このことは $\mathrm{Mn} ， \mathrm{Si} な$ どの作用により固体鉄中の酸素溶解度がまし, 凝固時に 生成した $\mathrm{Mn}, \mathrm{Si}$ 采の酸化物が，均熱中に地鉄中に溶 解して, その酸化物の形態, 組成を变えるものと思われ る.

\section{文献}

1) 佐野, 伊藤, 三輪, 久田: 鉄と鋼, 54 (1968), s. 513

2 ) S. $N$. Corney and E. T. Turkdogan: J. Iron Steel Inst., 180 (1955), p. 344

3) E. T. Turkdogan and $S$. Ignatowitz: J. Iron Steel Inst., 183 (1958), p. 242

4) H. A. Wriedt and O. D. Gonzalez: Trans. AIME, 221 (1961), p. 532

5) $R$. W. Fountain and Chipman: Trans. AIME, 212 (1958), p. 737

6 ) 盛, 新名, 一瀬, 諸岡: 金属学会誌. 27 (1963), p. 49

7 ) 盛, 新名, 一瀬, 小山：金属学会誌, 27 (1963), p. 53

8 ) 盛, 一瀬: 金属学会誌, 28 (1964), p. 145

9 ) E. T. Turkdogan and S. Ignatowitz: J. Iron Steel Inst., 180 (1955), p. 349

10) T. R. MAGER: Trans. AIME, 230 (1964); p. 773

11) H. C. Fiedler: Trans. AIME, 239 (1967), p. 260

12) 和田, 斎藤：金属学会誌，25(1961), p. 159

13) 和田, 郡司, 和田: 学振 19 委, 8030 (1966),

14）草野，伊藤，佐野：鉄と鋼，54 (1968), p. 553

15) 的場, 郡司: 鉄と鋼, 49 (1963), p. 758

16) 坂尾, 佐野: 金属学会誌, 26 (1962), p. 30

17) 学振製鋼 19 委: 製鋼反応の推奖平衡值 (1968) p. 40, p. 71, p. 91, p. 109 ，[日刊工業新聞社] 